\title{
Evapotranspiration Estimation Based on the Complementary Relationships
}

\author{
Virginia Venturini ${ }^{1}$, Carlos Krepper ${ }^{1,2}$ and Leticia Rodriguez ${ }^{1}$ \\ ${ }^{1}$ Centro de Estudios Hidro-Ambientales-Facultad de Ingeniería y \\ Ciencias Hídricas Universidad Nacional del Litoral \\ ${ }^{2}$ Consejo Nacional de Investigaciones Científicas y Técnicas \\ Argentina
}

\section{Introduction}

Many hydrologic modeling and agricultural management applications require accurate estimates of the actual evapotranspiration (ET), the relative evaporation (F) and the evaporative fraction (EF). In this chapter, we define ET as the actual amount of water that is removed from a surface due to the processes of evaporation-transpiration whilst the potential evapotranspiration (Epot) is any other evaporation concept. There are as many potential concepts as developed mathematical formulations. In this chapter, F represents the ratio between ET and Epot, as it was introduced by Granger \& Gray (1989). Meanwhile, EF is the ratio of latent flux over available energy.

It is worthy to note that, in general, the available evapotranspiration concepts and models involve three sets of variables, i.e. available net radiation (Rn), atmospheric water vapor content or temperature and the surface humidity. Hence, different Epot formulations were derived with one or two of those sets of variables. For instance, Penman (1948) established an equation by using the Rn and the air water vapor pressure. Priestley \& Taylor (1972) derived their formulations with only the available Rn.

In the last three decades, several models have been developed to estimate ET for a wide range of spatial and temporal scales provided by remote sensing data. The methods could be categorized as proposed by Courault et al. (2005).

Empirical and semi-empirical methods: These methods use site specific or semi-empirical relationships between two o more variables. The models proposed by Priestley \& Taylor (1972), hereafter referred to as P-T, Jackson et al. (1977); Seguin et al. (1989); Granger \& Gray (1989); Holwill \& Stewart (1992); Carlson et al. (1995); Jiang \& Islam (2001) and Rivas \& Caselles (2004), lie within this category.

Residual methods: This type of models commonly calculates the energy budged, then ET is estimated as the residual of the energy balance. The following models are examples of residual methods: The Surface Energy Balance Algorithm for Land (SEBAL) (Bastiaanssen et al., 1998; Bastiaanssen, 2000), the Surface Energy Balance System (SEBS) model (Su, 2002) and the two-source model proposed by Norman et al. (1995), among others.

Indirect methods: These physically based methods involve Soil-Vegetation-Atmosphere Transfer (SVAT) models, presenting different levels of complexity often reflected in the number of parameters. For example, the ISBA (Interactions between Soil, Biosphere, and 
Atmosphere) model by Noilhan \& Planton (1989), developed to be included within large scale meteorological models, parameterizes the land surface processes. The ISBA Ags model (Calvet et al., 1998) improved the canopy stomatal conductance and $\mathrm{CO}_{2}$ concentration with respect to the ISBA original model.

Among the first category (Empirical and semi-empirical methods), only few methodologies to calculate ET have taken advantage of the complementary relationship (CR).

It is worth mentioning that there are only two CR approaches known so far, one attributed to Bouchet (1963) and the other to Granger \& Gray (1989). Even though various ET models derived from these two fundamental approaches are referenced to throughout the chapter, it is not the intention of the authors to review them in detail.

Bouchet (1963) proposed the first complementary model based on an experimental design. He postulated that, for a large homogeneous surface and in absence of advection of heat and moisture, regional ET could be estimated as a complementary function of Epot and the wet environment evapotranspiration $(\mathrm{Ew})$ for a wide range of available energy. Ew is the ET of a surface with unlimited moisture. Thus, if Epot is defined as the evaporation that would occur over a saturated surface, while the energy and atmospheric conditions remain unchanged, it seems reasonable to anticipate that Epot would decrease as ET increases. The underlying argument is that ET incorporates humidity to the surface sub-layer reducing the possibility for the atmosphere to transport that humidity away from the surface. Bouchet's idea that Epot and ET have this complementary relationship has been the subject of many studies and discussions, mainly due to its empirical background (Brutsaert \& Parlange, 1998; Ramírez et al., 2005). Examples of successful models based on Bouchet's heuristic relationship include those developed by Brutsaert \& Stricker (1979); Morton (1983) and Hobbins et al. (2001). These models have been widely applied to a broad range of surface and atmospheric conditions (Brutsaert \& Parlange, 1998; Sugita et al., 2001; Kahler \& Brutsaert, 2006; Ozdogan et al., 2006; Lhomme \& Guilioni, 2006; Szilagyi, 2007; Szilagyi \& Jozsa, 2008).

Granger (1989a) developed a physically based complementary relationship after a meticulous analysis of potential evaporation concepts. He remarked that "Bouchet corrected the misconception that a larger potential evaporation necessarily signified a larger actual evaporation". The author used the term "potential evaporation" for the Epot and Ew concepts, and clearly presented the complementary behavior of common potential evaporation theories. This author suggested that Ew is the value of the potential evaporation when the actual evaporation rate is equal to the potential rate. The use of two potential parameters, i.e. Epot and Ew, seems to generate a universal relationship, and therefore, universal ET models. Conversely, attempting to estimate ET from only one potential formulation may need site-specific calibration or auxiliary relationships (Granger, 1989b). In addition, the relative evaporation coefficient introduced by Granger \& Gray (1989) enhances the complementary relationship with a dimensionless coefficient that yields a simpler complementary model.

The foundation of the complementary relationship is the basis for operational estimates of areal ET by Morton (1983), who formulated the Complementary Relationship Areal Evapotranspiration (CRAE) model. The reliability of the independent operational estimates of areal evapotranspiration was tested with comparable, long-term water budget estimates for 143 river basins in North America, Africa, Ireland, Australia and New Zealand.

A procedure to calculate ET requiring only common meteorological data was presented by Brutsaert \& Stricker (1979). Their Advection-Aridity approach (AA) is based on a conceptual 
model involving the effect of the regional advection on potential evaporation and Bouchet's complementary model. Thus, the aridity of the region is deduced from the regional advection of the drying power of the air. The authors validated their model in a rural watershed finding a good agreement between estimated daily ET and ET obtained with the energy budget method.

Morton's CRAE model was tested by Granger \& Gray (1990) for field-size land units under a specific land use, for short intervals of time such as 1 to 10 days. They examined the CRAE model with respect to the algorithms used to describe different terms and its applicability to reduced spatial and temporal scales. The assumption in CRAE that the vapor transfer coefficient is independent of wind speed may lead to appreciable errors in computing ET. Comparisons of ET estimates and measurements demonstrated that the assumptions that the soil heat flux and storage terms are negligible, lead to large overestimation by the model during periods of soil thaw.

Hobbins et al. (2001) and Hobbins \& Ramírez (2001) evaluated the implementations of the complementary relationship hypothesis for regional evapotranspiration using CRAE and AA models. Both models were assessed against independent estimates of regional evapotranspiration derived from long-term, large-scale water balances for 120 minimally impacted basins in the conterminous United States. The results suggested that CRAE model overestimates annual evapotranspiration by $2.5 \%$ of mean annual precipitation, whereas the AA model underestimates annual evapotranspiration by $10.6 \%$ of mean annual precipitation. Generally, increasing humidity leads to decreasing absolute errors for both models. On the contrary, increasing aridity leads to increasing overestimation by the CRAE model and underestimation by the AA model, except at high aridity basins, where the AA model overestimates evapotranspiration.

Three evapotranspiration models using the complementary relationship approach for estimating areal ET were evaluated by $\mathrm{Xu} \&$ Singh (2005). The tested models were the CRAE model, the AA model, and the model proposed by Granger \& Gray (1989) (GG), using the concept of relative evaporation. The ET estimates were compared in three study regions representing a wide geographic and climatic diversity: the NOPEX region in Central Sweden (typifying a cool temperate humid region), the Baixi catchment in Eastern China (typifying a subtropical, humid region), and the Potamos tou Pyrgou River catchment in Northwestern Cyprus (typifying a semiarid to arid region). The calculation was made on a daily basis whilst comparisons were made on monthly and annual bases. The results showed that using the original parameter values, all three complementary relationship models worked reasonably well for the temperate humid region, while their predictive power decreased as soil moisture exerts increasing control over the region, i.e. increased aridity. In such regions, the parameters need to be calibrated.

Ramírez et al. (2005) provided direct observational evidence of the complementary relationship in regional evapotranspiration hypothesized by Bouchet in 1963. They used independent observations of ET and Epot at a wide range of spatial scales. This work is the first to assemble a data set of direct observations demonstrating the complementary relationship between regional ET and Epot. These results provided strong evidence for the complementary relationship hypothesis, raising its status above that of a mere conjecture.

A drawback among the aforementioned complementary ET models is the use of Penman or Penman-Monteith equation (Monteith \& Unsworth, 1990) to estimate Epot. Specifically, the Morton's CRAE model (Morton, 1983) uses Penman equation to calculate Epot, and a modified P-T equation to approximate Ew. Brutsaert \& Stricker (1979) developed their AA 
model using Penman for Epot and the P-T equilibrium evaporation to model Ew. At the time those models were developed, networks of meteorological stations constituted the main source of atmospheric data, while the surface temperature (Ts) or the soil temperature were available only at some locations around the World. The advent of satellite technology provided routinely observations of the surface temperature, but the source of atmospheric data was still ancillary. Thus, many of the current remote sensing approaches were developed to estimate ET with little amount of atmospheric data (Price, 1990; Jiang \& Islam, 2001).

The recent introduction of the Atmospheric Profiles Product derived from Moderate Resolution Imaging Spectroradiometer (MODIS) sensors onboard of EOS-Terra and EOSAqua satellites meant a significant advance for the scientific community. The MODIS Atmospheric profile product provides atmospheric and dew point temperature profiles on a daily basis at 20 vertical atmospheric pressure levels and at $5 \times 5 \mathrm{~km}$ of spatial resolution (Menzel et al., 2002). When combined with readily available Ts maps obtained from different sensors, this new remote source of atmospheric data provides a new opportunity to revise the complementary relationship concepts that relate ET and Epot (Crago \& Crowley, 2005; Ramírez et al., 2005).

A new method to derive spatially distributed EF and ET maps from remotely sensed data without using auxiliary relationships such as those relating a vegetation index (VI) with the land surface temperature (Ts) or site-specific relationships, was proposed by Venturini et al. (2008). Their method for computing ET is based on Granger's complementary relationship, the P-T equation and a new parameter introduced to calculate the relative evaporation ( $\mathrm{F}=\mathrm{ET} /$ Epot). The ratio $\mathrm{F}$ can be expressed in terms of $\mathrm{Tu}$, which is the temperature of the surface if it is brought to saturation without changing the actual surface vapor pressure. The concept of Tu proposed by these authors is analogous to the dew point temperature $(\mathrm{Td})$ definition.

Szilagyi \& Jozsa (2008) presented a long term ET calculation using the AA model. In their work the authors presented a novel method to calculate the equilibrium temperature of Ew and P-T equation that yields better long-term ET estimates. The relationship between ET and Epot was studied at daily and monthly scales with data from 210 stations distributed all across the USA. They reported that only the original Rome wind function of Penman yields a truly symmetric CR between ET and Epot which makes Epot estimates true potential evaporation values. In this case, the long-term mean value of evaporation from the modified AA model becomes similar to CRAE model, especially in arid environments with possible strong convection. An $\mathrm{R}^{2}$ of approximately 0.95 was obtained for the 210 stations and all wind functions used. Likewise, Szilagyi \& Jozsa in (2009) investigated the environmental conditions required for the complementary ET and Epot relationship to occur. In their work, the coupled turbulent diffusion equations of heat and vapor transport were solved under specific atmospheric, energy and surface conditions. Their results showed that, under nearneutral atmospheric conditions and a constant energy term at the evaporating surface, the analytical solution across a moisture discontinuity of the surface yields a symmetrical complementary relationship assuming a smooth wet area.

Recently, Crago et al. (2010) presented a modified AA model in which the specific humidity at the minimum daily temperature is assumed equal to the daily average specific humidity. The authors also modified the drying power calculation in Penman equation using MoninObukhov theory (Monin \& Obukhov, 1954). They found promising results with these modifications. Han et al. (2011) proposed and verified a new evaporation model based on 
the AA model and the Granger's CR model (Granger, 1989b). This newly proposed model transformed Granger's and AA models into similar, dimensionless forms by normalizing the equations with Penman potential model. The evaporation ratio (i.e. the ratio of ET to Penman potential evaporation) was expressed as a function of dimensionless variables based on radiation and atmospheric conditions. From the validation with ground observations, the authors concluded that the new model is an enhanced Granger`s model, with better evaporation predictions. In addition, the model somewhat approximates the AA model under neither too-wet nor too-dry conditions. As the reader can conclude, the complementary approach is nowadays the subject of many ongoing researches.

\section{A review of Bouchet's and Granger's models}

Bouchet (1963) set an experiment over a large homogeneous surface without advective effects. Initially, the surface was saturated and evaporated at potential rate. With time, the region dried, but a small parcel was kept saturated (see Figure 1), evaporating at potential rate. The region and the parcel scales were such that the atmosphere could be considered stable. Bouchet described his experiment, dimension and scales as follows ${ }^{1}$,

- The energy balance requires the prior definition of the limits of the system. To avoid taking into account the phenomena of accumulation and restoration of heat during the day and night phases, the assessment will cover a period of 24 hours.

- The system includes an ensemble of vegetation, soil, and a portion of the lower atmosphere. The sizes of these layers are such that the daily temperature variations are not significant.

- If this system is located in an area which, for any reason, does not have the same climatic characteristics, there will be exchanges of energy throughout the side "walls" of the system, that need to be analyzed (advection free area).

- Lateral exchanges by conduction in the soil are negligible. The lateral exchanges in the atmosphere due to the homogenization of the air masses will be named as "oasis effect". Given the heterogeneity from one point to another, the lateral exchanges of energies, or the "oasis effect", rule the natural conditions.

- The oasis effect phenomenon can be schematically represented as shown in Figure 1. If in a flat, homogeneous area (brown line in Figure 1), a discontinuity appears, i.e. a change in soil specific heat, moisture or natural vegetation cover, etc. (green line in Figure 1), then a disturbed area is developed in the direction of airflow (gray filled area in Figure 1) where environmental factors are modified from the general climate because of the discontinuity.

- The perturbation raises less in height than in width. It always presents a "flat lens" shape in which the thickness is small compared to the horizontal dimensions.

As mentioned, initially the surface was saturated and evaporated at its potential rate, i.e. at the so-called reference evapotranspiration (or Ew). In this initial condition, Epot $=\mathrm{Ew}=\mathrm{ET}$. When ET is lower than Ew due to limited water availability, a certain excess of energy would become available. This remaining energy not used for evaporation may, in tern, warm the lower layer of the atmosphere. The resulting increase in air temperature due to the heating, and the decrease in humidity caused by the reduction of ET, would lead to a new value of Epot larger than Ew by the amount of energy left over.

${ }^{1}$ The following text was translated by the authors of this chapter from Bouchet's original paper (in French). 


\section{General Climate of the External System}

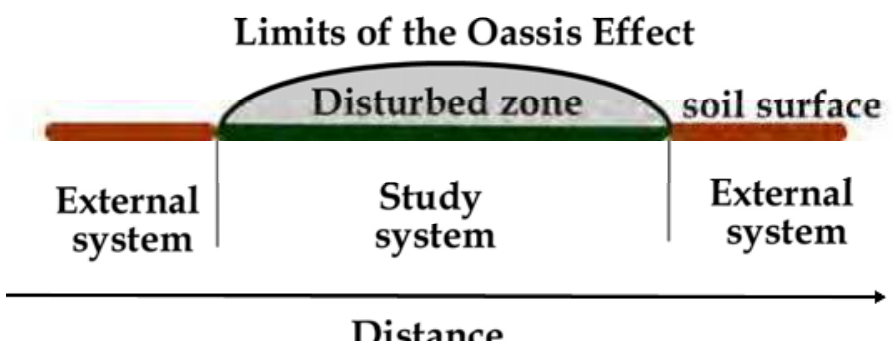

Fig. 1. Reproduction of Bouchet's schematic representation of the Oasis Effect experiment.

Thus, Bouchet's complementary relationship was obtained from the balance of these evaporation rates,

$$
E T+E p o t=2 E w
$$

Bouchet postulated that in such a system, under a constant energy input and away from sharp discontinuities, there exists a complementary feedback mechanism between ET and Epot, that causes changes in each to be complementary, that is, a positive change in ET causes a negative change in Epot (Ozdogan et al., 2006), as sketched in Figure 2. Later, Morton (1969) utilized Bouchet's experiment to derive the potential evaporation as a manifestation of regional evapotranspiration, i.e. the evapotranspiration of an area so large that the heat and water vapor transfer from the surface controls the evaporative capacity of the lower atmosphere.

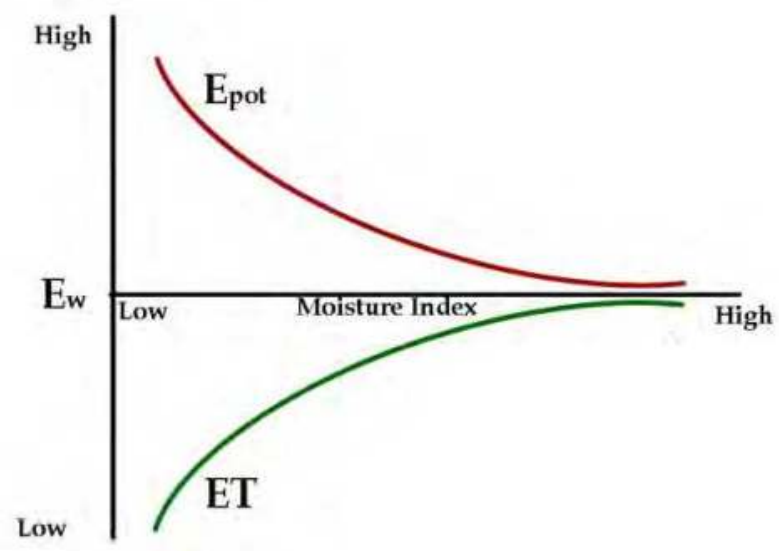

Fig. 2. Sketch of Bouchet's complementary ET and Epot relationship

The hypothesis asserts that when ET falls below Ew as a result of limited moisture availability, a large quantity of energy becomes available for sensible heat flux that warms and dries the atmospheric boundary layer thereby causing Epot to increase, and vise versa. 
Equation (1) holds true if the energy budget remains unchanged and all the excess energy goes into sensible heat (Ramírez et al., 2005). It should be noted that Bouchet's experimental system is the so-called advection-free-surface in P-T formulation.

This relationship assumes that as ET increases, Epot decreases by the same amount, i.e. $\delta E T$ $=-\delta$ Epot, where the symbol $\delta$ means small variations. Bouchet's equation has been widely used in conjunction with Penman (1948) and Priestley-Taylor (1972) (Brutsaert \& Stricker, 1979; Morton, 1983; Hobbins el al., 2001).

Granger (1989b) argued that the above relationship lacked a theoretical background, mainly due to Bouchet's symmetry assumption $(\delta E T=-\delta E p o t)$. Nonetheless, the author recognized that Bouchet's CR set the basis for the complementary behavior between two potential concepts of evaporation and ET. One of the benefits of using two potential evaporation concepts rather than a single one is that the resulting CR would be universal, without the need of tuning parameters from local data.

Granger (1989a) revised the diversity of potential evaporation concepts available at that moment and expertly established an inequity among them. The resulting comparison yielded that Penman (1948) and Priestley \& Taylor (1972) concepts are Ew concepts, and that the true potential evaporation would be that proposed by van Bavel (1966). Thus, these parameterizations would result in the following inequity, Epot $\geq \mathrm{Ew} \geq \mathrm{ET}$, where Epot would be van Bavel's concept, Ew could be obtained with either Penman or P-T, knowing that ET-Penman is larger than ET-Priestley-Taylor (Granger, 1989a). Hence, the author postulated that the above inequity comprises Bouchet's equity $(\delta \mathrm{ET}=-\delta \mathrm{Epot})$ but it is based on a new CR. Granger (1989b) then proposed the following CR formulation,

$$
E T+E p o t \frac{\gamma}{\Delta}=E w\left(\frac{\Delta+\gamma}{\Delta}\right)
$$

where $\gamma$ is the psychrometric constant and $\Delta$ is the slope of the saturation vapor pressure (SVP) curve.

Equation (2) shows that for constant available energy and atmospheric conditions, $-\gamma / \Delta$ is equal to the ratio $\delta E T / \delta E$ pot. In addition, this CR is not symmetric with respect to Ew. It can be easily verified that equation (2) is equivalent to equation (1) when $\gamma=\Delta$. The condition that the slope of the SVP curve equals the psychrometric constant is only true when the temperature is near $6{ }^{\circ} \mathrm{C}$ (Granger, 1989b). This has been widely tested (Granger \& Gray, 1989; Crago \& Crowley, 2005; Crago et al., 2005; Xu \& Singh, 2005; Venturini et al., 2008; Venturini et al., 2011).

\section{Bouchet's versus Granger’s complementary models}

A review of the two complementary models widely used for ET calculations was presented. Both methods are not only conceptually different, but also differ in their derivations. Mathematically speaking, Bouchet's complementary relationship (equation 1) results a simplification of Granger's complementary equation (equation 2) for the case $\Delta=\gamma$. Equations (1) and (2) can also be written, respectively, as follows,

$$
\frac{1}{2} E T+\frac{1}{2} E p o t=E w
$$




$$
\left(\frac{\Delta}{\Delta+\gamma}\right) E T+\left(\frac{\gamma}{\Delta+\gamma}\right) E p o t=E w
$$

The re-written Bouchet's complementary model, equation (3), clearly expresses Ew as the middle point between the ET and the Epot processes. In contrast, the re-written Granger's complementary relationship, equation (4), shows how both, ET and Epot contribute to Ew with different coefficients, the coefficients varying with the slope of the SVP curve at the air temperature Ta, since $\gamma$ is commonly assumed constant. For clarity, Table 1 summarizes all symbols and definitions used in this Chapter.

Recently, Ramírez et al., (2005) discussed Bouchet's coefficient "2" with monthly average ground measurements. In their application, Epot was calculated with the Penman-Monteith equation and Ew with the P-T model. They concluded that the appropriate coefficient should be slightly lower than 2 .

Venturini et al. (2008) and Venturini et al. (2011) introduced the concept of the relative evaporation, F= ET/Epot, proposed earlier by Granger \& Gray (1989), along with P-T equation in both CR models. Thus, Epot is replaced by ET/F and Ew is equated to P-T equation. Hence, replacing Epot in equation (3),

$$
E T+\frac{E T}{F}=k E w
$$

where $\mathrm{k}$ is Bouchet's coefficient, originally assumed $\mathrm{k}=2$

Then, when Ew is replaced in (5) by the P-T equation, results

$$
E T\left(1+\frac{1}{F}\right)=k a(\mathrm{Rn}-G) \frac{\Delta}{\Delta+\gamma}
$$

where $\alpha$ is the P-T's coefficient, and the rest of the variables are defined in Table 1. Finally, Bouchet's CR is obtained by rearranging the terms in equation (6),

$$
E T=k a\left(\frac{F}{F+1}\right)\left(\frac{\Delta}{\Delta+\gamma}\right)(\mathrm{Rn}-G)
$$

Following the same procedure with equation (4), the equivalent equation for Granger's CR model is,

$$
E T=\alpha\left(\frac{F \Delta}{F \Delta+\gamma}\right)(\mathrm{Rn}-G)
$$

It should be noted that the underlying assumptions of equation (7) are the same as those behind equation (8), plus the condition that $\Delta$ is approximately equal to $\gamma$.

Both, equations (7) and (8), require calculating the $\mathrm{F}$ parameter, otherwise the equations would have only theoretical advantages and would not be operative models. Venturini et al. (2008) developed an equation for F that can be estimated using MODIS products. Their F method is briefly presented here.

Consider the relative evaporation expression proposed by Granger \& Gray (1989),

$$
\frac{\mathrm{ET}}{\text { Epot }}=\frac{f_{u}\left(\mathrm{e}_{\mathrm{s}}-\mathrm{e}_{\mathrm{a}}\right)}{f_{u}\left(\mathrm{e}_{\mathrm{s}}^{*}-\mathrm{e}_{\mathrm{a}}\right)}
$$


where $f_{u}$ is a function of the wind speed and vegetation height, $e_{s}$ is the surface actual water vapor pressure, $e_{a}$ is the air actual water vapor pressure, $e_{s}^{*}$ is the surface saturation water vapor pressure.

\begin{tabular}{|l|l|}
\hline Symbol & Definition \\
\hline$\alpha$ & Priestley \& Taylor's coefficient. $\alpha=1.26$ \\
\hline$\Delta\left[\mathrm{hPa} /{ }^{\circ} \mathrm{C}\right]$ & Slope of the saturation water vapor pressure curve \\
\hline$\gamma\left[\mathrm{hPa} /{ }^{\circ} \mathrm{C}\right]$ & Psychrometric constant \\
\hline$\lambda \mathrm{E}\left[\mathrm{W} \mathrm{m}{ }^{-2}\right]$ & Latent heat flux density \\
\hline $\mathrm{e}_{\mathrm{a}}[\mathrm{hPa}]$ & Air actual water vapor pressure at Td \\
\hline $\mathrm{e}^{*}[\mathrm{hPa}]$ & Air saturation water vapor pressure at Ta \\
\hline $\mathrm{e}_{\mathrm{s}}[\mathrm{hPa}]$ & Surface actual water vapor pressure at Tu \\
\hline $\mathrm{e}^{*}[\mathrm{hPa}]$ & Surface saturation water vapor pressure at Ts \\
\hline $\mathrm{Ew}\left[\mathrm{W} \mathrm{m}{ }^{-2}\right]$ & Evapotranspiration of wet environment \\
\hline $\mathrm{Epot}\left[\mathrm{W} \mathrm{m}{ }^{-2}\right]$ & Potential evapotranspiration \\
\hline$f_{u}$ & Wind function \\
\hline $\mathrm{F}$ & Relative evaporation coefficient of Venturini et al. (2008) \\
\hline $\mathrm{G}\left[\mathrm{W} \mathrm{m}{ }^{-2}\right]$ & Soil heat flux \\
\hline $\mathrm{H}\left[\mathrm{W} \mathrm{m} \mathrm{m}^{-2}\right]$ & Sensible heat flux \\
\hline $\mathrm{Q}\left[\mathrm{W} \mathrm{m}{ }^{-2}\right]$ & Available energy, $(\mathrm{Rn}-\mathrm{G})$ \\
\hline $\mathrm{Rn}\left[\mathrm{W} \mathrm{m}{ }^{-2}\right]$ & Net radiation at the surface \\
\hline $\mathrm{Ta}\left[{ }^{\circ} \mathrm{K}\right]$ or $\left[{ }^{\circ} \mathrm{C}\right]$ & Air temperature \\
\hline $\mathrm{Td}\left[{ }^{\circ} \mathrm{K}\right]$ or $\left[{ }^{\circ} \mathrm{C}\right]$ & Dew point temperature \\
\hline $\mathrm{Ts}\left[{ }^{\circ} \mathrm{K}\right]$ or $\left[{ }^{\circ} \mathrm{C}\right]$ & Surface temperature \\
\hline $\mathrm{Tu}\left[{ }^{\circ} \mathrm{K}\right]$ or $\left[{ }^{\circ} \mathrm{C}\right]$ & $\begin{array}{l}\text { Surface temperature if the surface is brought to saturation without } \\
\text { changing e }\end{array}$ \\
\hline
\end{tabular}

Table 1. Symbols and units

This form of the relative evaporation equation needs readily available meteorological data. A key difficulty in applying equation (9) lies on the estimation of $\left(e_{s}-e_{a}\right)$, since there is no simple way to relate $e_{s}$ to any readily available surface temperature. Thus, a new temperature should be defined. Many studies have used temperature as a surrogate for vapor pressure (Monteith \& Unsworth, 1990; Nishida et al., 2003). Although the relationship between vapor pressure and temperature is not linear, it is commonly linearized for small temperature differences. Hence, $\mathrm{e}_{\mathrm{s}}$ and $\mathrm{e}_{\mathrm{s}}{ }^{*}$ should be related to soil+vegetation at a temperature that would account for water vapor pressure. Figure 3 shows the relationship between $\mathrm{e}_{\mathrm{s}}, \mathrm{e}_{\mathrm{s}}{ }_{\mathrm{s}}$ and $\mathrm{e}_{\mathrm{a}}$ and their corresponding temperatures; where $\mathrm{e}_{\mathrm{u}}{ }^{*}$ is the SVP at an unknown surface temperature Tu.

An analogy to the dew point temperature concept (Td) suggests that $\mathrm{Tu}$ would be the temperature of the surface if the surface is brought to saturation without changing the surface actual water vapor pressure. Accordingly, Tu must be lower than Ts if the surface is not saturated and close to Ts if the surface is saturated. Consequently, $\mathrm{e}_{\mathrm{s}}$ could be derived from the temperature Tu. Although Tu may not possibly be observed in the same way as $\mathrm{Td}$, it can be derived, for instance, from the slope of the exponential SVP curve as a function of Ts and Td. This calculation is further discussed later in this chapter. 
Assuming that the surface saturation vapor pressure at $\mathrm{Tu}$ would be the actual soil vapor pressure and that the SVP can be linearized, $\left(\mathrm{e}_{\mathrm{s}}-\mathrm{e}_{\mathrm{a}}\right)$ can be approximated by $\Delta_{1}(\mathrm{Tu}-\mathrm{Td})$ and $\left(e_{s}^{*}-e_{a}\right)$ by $\Delta_{2}(T s-T d)$, respectively. Figure 3 shows a schematic of these concepts.

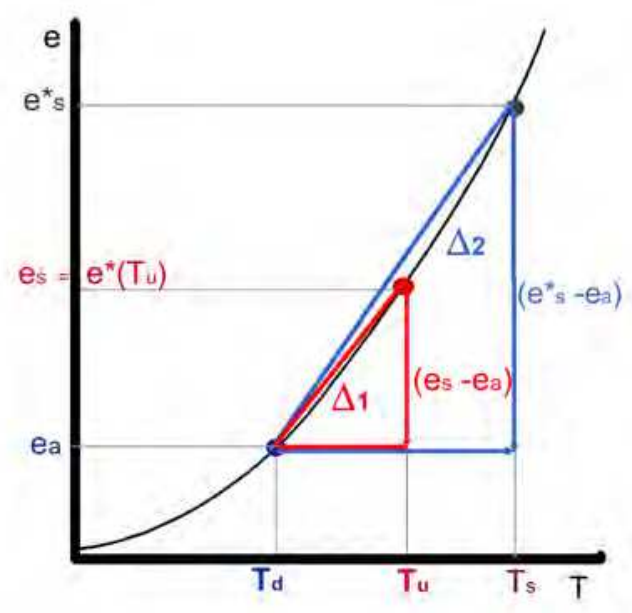

Fig. 3. Schematic of the linearized saturation vapor pressure curve and the relationship between $\left(\mathrm{e}_{\mathrm{s}}-\mathrm{e}_{\mathrm{a}}\right)$ and $\Delta_{1}(\mathrm{Tu}-\mathrm{Td})$, and $\left(\mathrm{e}_{\mathrm{s}}^{*}-\mathrm{e}_{\mathrm{a}}\right)$ and $\Delta_{2}(\mathrm{Ts}-\mathrm{Td})$.

Therefore, ET/Epot (see equation 9) can be rewritten as follows,

$$
\mathrm{F}=\frac{\mathrm{ET}}{\mathrm{Epot}}=\frac{(\mathrm{Tu}-\mathrm{Td})}{(\mathrm{Ts}-\mathrm{Td})}\left(\frac{\Delta_{1}}{\Delta_{2}}\right)
$$

The wind function, $\mathrm{f}_{\mathrm{u}}$, depends on the vegetation height and the wind speed, but it is independent of surface moisture. In other words, it is reasonable to expect that the wind function will affect ET and Epot in a similar fashion (Granger, 1989b), so its effect on ET and Epot cancels out. The slopes of the SVP curve, $\Delta_{1}$ and $\Delta_{2}$, can be computed from the SVP first derivative at $\mathrm{Td}$ and Ts without adding further complexity to this method. However, $\Delta_{1}$ and $\Delta_{2}$ will be assumed approximately equal from now on, as they will be estimated as the first derivative of the SVP at Ta.

The relationship between Ts and Tu can be examined throughout the definition of $\mathrm{Tu}$, which represents the saturation temperature of the surface. For a saturated surface, Tu is expected to be very close or equal to Ts. In contrast, for a dry surface, Ts would be much larger than $\mathrm{Tu}$. Since Epot is larger than or equal to ET, F ranges from 0 to 1 . For a dry surface, with Ts >> Tu, (Ts-Td) would be larger than (Tu-Td) and ET/Epot would tend to 0 . In the case of a saturated surface with $\mathrm{e}_{\mathrm{s}}$ close to $\mathrm{e}_{\mathrm{s}}{ }^{*}$ and $\mathrm{Ts}$ close to $\mathrm{Tu}$, (Ts-Td) would be similar to (Tu-Td) and ET/Epot would tend to 1.

The calculation of Tu proposed by Venturini et al. (2008) is presented in the next section, where results from MODIS data are shown. However, it is emphasized that the definition of $\mathrm{Tu}$ is not linked to any data source; therefore it can be estimated with different approaches. 


\section{Complementary models application using remotely sensed data}

In order to show the potential of the complementary relationships, equations (7) and (8) were applied to the Southern Great Plains of the USA region and the results compared and analyzed.

\subsection{Study area}

The Southern Great Plains (SGP) region in the United States of America extends over the State of Oklahoma and southern parts of Kansas. The area broadens in longitude from $95.3^{\circ}$ $\mathrm{W}$ to $99.5^{\circ} \mathrm{W}$ and in latitude from $34.5^{\circ} \mathrm{N}$ to $38.5^{\circ} \mathrm{N}$ (Figure 4). This region was the first field measurement site established by the Atmospheric Radiation Measurement (ARM) Program. At present, the ARM program has three experimental sites. Scientists from all over the World are using the information obtained from these sites to improve the performance of atmospheric general circulation models used for climate change research. The SGP was chosen as the first ARM field measurement site for several reasons, among them, its relatively homogeneous geography, easy accessibility, wide variability of climate cloud types, surface flux properties, and large seasonal variations in temperature and specific humidity (http://www.arm.gov/sites/sgp).

Most of this region is characterized by irregular plains. Altitudes range from approximately $500 \mathrm{~m}$ to $90 \mathrm{~m}$, increasing gradually from East to West. In southwestern Oklahoma, the highest Wichita Mountains rise as much as $800 \mathrm{~m}$ above the surrounding landscape (Heilman \& Brittin, 1989; Venturini et al., 2008). The climate is semiarid-subtropical. Although the maximum rainfall occurs in summer, high temperatures make summer relatively dry. Average annual temperatures range from $14^{\circ} \mathrm{C}$ to $18^{\circ} \mathrm{C}$. Winters are cold and dry, and summers are warm to hot. The frost-free season stretches from 185 to 230 days. Precipitation ranges from 490 to $740 \mathrm{~mm}$, with most of it falling as rain.

Grass is the dominant prairie vegetation. Most of it is moderately tall and usually grows in bunches. The most prevalent type of grassland is the bluestem prairie (Andropogon gerardii and Andropogon hallii), along with many species of wildflowers and legumes. In many places where grazing and fire are controlled, deciduous forest is encroaching on the prairies.
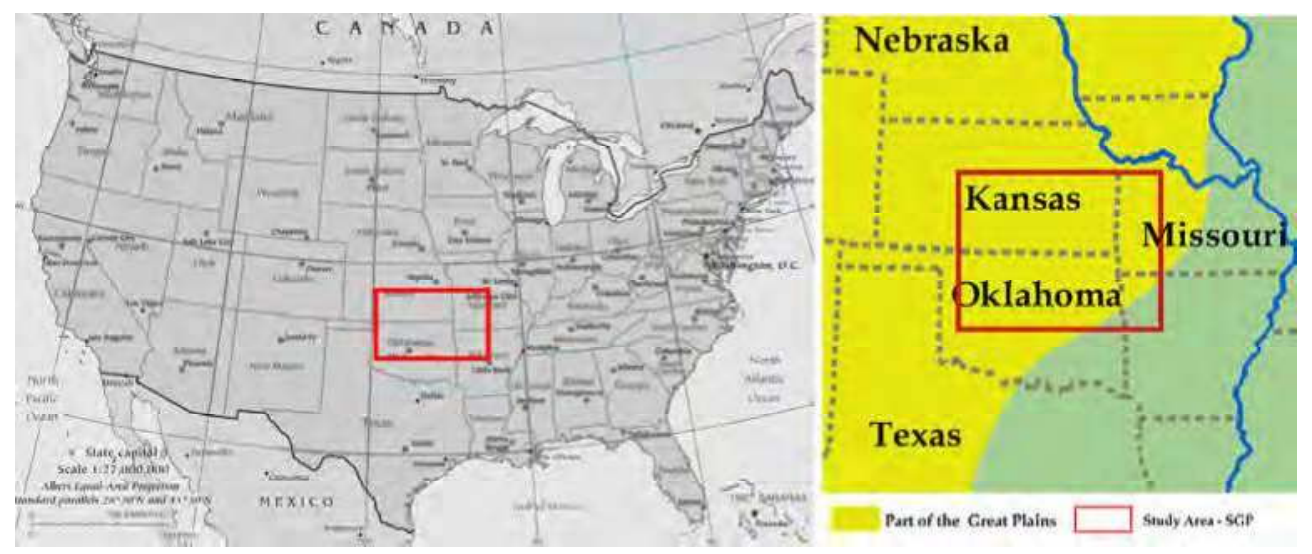

Fig. 4. Study area map 
Due to generally favorable conditions of climate and soil, most of the area is cultivated, and little of the original vegetation remains intact. Oak savanna occurs along the eastern border of the region and along some of the major river valleys.

\subsection{Ground data availability}

The latent heat data was obtained from the ARM program Web site (http://www.arm.gov). The ARM instruments and measurement applications are well established and have been used for validation purposes in many studies (Halldin \& Lindroth, 1992; Fritschen \& Simpson, 1989). The site and name, elevation, geographic coordinates (latitude and longitude) and surface cover of the stations used in this work are shown in Table 2.

\begin{tabular}{|l|c|c|c|}
\hline \multicolumn{1}{|c|}{ Site } & $\begin{array}{c}\text { Elevation } \\
\text { (m a.m.s.l.) }\end{array}$ & Lat/Lon & Vegetation Type \\
\hline Ashton, Kansas E-9 & 386 & $37.133 \mathrm{~N} / 97.266 \mathrm{~W}$ & Pasture \\
\hline Coldwater, Kansas E-8 & 664 & $37.333 \mathrm{~N} / 99.309 \mathrm{~W}$ & Rangeland (grazed) \\
\hline Cordell, Oklahoma: E-22 & 465 & $35.354 \mathrm{~N} / 98.977 \mathrm{~W}$ & Rangeland (grazed) \\
\hline Cyril, Oklahoma: E-24 & 409 & $34.883 \mathrm{~N} / 98.205 \mathrm{~W}$ & Wheat (gypsum hill) \\
\hline Earlsboro, Oklahoma: E-27 & 300 & $35.269 \mathrm{~N} / 96.740 \mathrm{~W}$ & Pasture \\
\hline Elk Falls, Kansas E-7 & 283 & $37.383 \mathrm{~N} / 96.180 \mathrm{~W}$ & Pasture \\
\hline El Reno, Oklahoma: E-19 & 421 & $35.557 \mathrm{~N} / 98.017 \mathrm{~W}$ & Pasture (ungrazed) \\
\hline Hillsboro, Kansas E-2 & 447 & $38.305 \mathrm{~N} / 97.301 \mathrm{~W}$ & Grass \\
\hline Lamont, Oklahoma: E-13 & 318 & $36.605 \mathrm{~N} / 97.485 \mathrm{~W}$ & Pasture and wheat \\
\hline Meeker, Oklahoma: E-20 & 309 & $35.564 \mathrm{~N} / 96.988 \mathrm{~W}$ & Pasture \\
\hline Morris, Oklahoma: E-18 & 217 & $35.687 \mathrm{~N} / 95.856 \mathrm{~W}$ & Pasture (ungrazed) \\
\hline Pawhuska, Oklahoma: E-12 & 331 & $36.841 \mathrm{~N} / 96.427 \mathrm{~W}$ & Native prairie \\
\hline Plevna, Kansas E-4 & 513 & $37.953 \mathrm{~N} / 98.329 \mathrm{~W}$ & Rangeland (ungrazed) \\
\hline Ringwood, Oklahoma: E-15 & 418 & $36.431 \mathrm{~N} / 98.284 \mathrm{~W}$ & Pasture \\
\hline
\end{tabular}

Table 2. Site name and station name, elevation, latitude, longitude and surface type

The first instrumentation installation to the SGP site took place in 1992, with data processing capabilities incrementally added in the succeeding years. This region has relatively extensive and well-distributed coverage of surface fluxes and meteorological observation stations. In this study, Energy Balance Bowen Ratio stations (EBBR), maintained by the ARM program were used for the validation of surface fluxes. The EBBR system produces 30 minute estimates of the vertical fluxes of sensible and latent heat at the local points. The EBBR fluxes estimates are calculated from observations of net radiation, soil surface heat flux, the vertical gradients of temperature and relative humidity.

\subsection{MODIS products}

The method proposed here was physically derived from universal relationships. Moreover, data sources do not represent a limitation for the applicability of equations (6) and (8), nonetheless remotely sensed data such as that provided by MODIS scientific team would empower the potential applications of the methods. Hence, the equations applicability using MODIS products was explored. The sensor's bands specifications can be obtained from http://modis.gsfc.nasa.gov/about/specifications.php. 
Daytime images for seven days in year 2003 with at least $80 \%$ of the study area free of clouds were selected. Table 3 summarizes the images information including date, day of the year, satellite overpass time and image quality.

Geolocation is the process by which scientists specify where a specific radiance signal was detected on the Earth's surface. The MODIS geolocation dataset, called MOD03, includes eight Earth location data fields, e.g. geodetic latitude and longitude, height above the Earth ellipsoid, satellite zenith angle, satellite azimuth, range to the satellite, solar zenith angle, and solar azimuth. Similarly Earth location algorithms are widely used in modeling and geometrically correct image data from the Land Remote Sensing Satellite (Landsat) Multispectral Scanner (MSS), Landsat Thematic Mapper (TM), System pour l'Observation de la Terre (SPOT), and Advanced Very High Resolution Radiometer (AVHRR) missions.

\begin{tabular}{|c|c|c|c|}
\hline Date in 2003 & $\begin{array}{c}\text { Day of the Year } \\
\text { (DOY) }\end{array}$ & $\begin{array}{c}\text { Overpass time } \\
\text { (UTC) }\end{array}$ & $\begin{array}{c}\text { Image Quality } \\
\text { (\% clouds) }\end{array}$ \\
\hline March $23^{\text {rd }}$ & 82 & $17: 05$ & 18 \\
\hline March $31^{\text {st }}$ & 90 & $17: 55$ & 15 \\
\hline April $1^{\text {st }}$ & 91 & $17: 00$ & 18 \\
\hline September $6^{\text {th }}$ & 249 & $17: 10$ & 23 \\
\hline September $19^{\text {th }}$ & 262 & $16: 40$ & 9 \\
\hline October $12^{\text {th }}$ & 285 & $16: 45$ & 6 \\
\hline October $19^{\text {th }}$ & 292 & $16: 50$ & 6 \\
\hline
\end{tabular}

Table 3. Date, Day of the Year, overpass time and image quality of the seven study days.

MOD11 is the Land Surface Temperature (LST), and emissivity product, providing per-pixel temperature and emissivity values. Average temperatures are extracted in Kelvin with a day/night LST algorithm applied to a pair of MODIS daytime and nighttime observations. This method yields $1 \mathrm{~K}$ accuracy for materials with known emissivities, and the view angle information is included in each LST product. The LST algorithms use other MODIS data as input, including geolocation, radiance, cloud masking, atmospheric temperature, water vapor, snow, and land cover. These products are validated, meaning that product uncertainties are well defined over a range of representative conditions. The theories behind this product can be found in Wan (1999), available at http://modis.gsfc.nasa.gov/ data/atbd/atbd_mod11.pdf.

In particular, MODIS Atmospheric Profile product consists on several parameters: total ozone burden, atmospheric stability, temperature and moisture profiles, and atmospheric water vapor. All of these parameters are produced day and night at $5 \times 5 \mathrm{~km}$ pixel resolution. There are two MODIS Atmosphere Profile data product files: MOD07_L2, containing data collected from the Terra platform and MYD07_L2 collecting data from Aqua platform. The MODIS temperature and moisture profiles are defined at 20 vertical levels. A simultaneous direct physical solution to the infrared radiative-transfer equation in a cloudless sky is used. The profiles are also utilized to correct for atmospheric effects for some of the MODIS products (e.g., sea-surface temperature and LST, ocean aerosol properties, etc) as well as to characterize the atmosphere for global greenhouse studies. Temperature and moisture profile retrieval algorithms are adapted from the International TIROS Operational Vertical Sounder (TOVS) Processing Package (ITPP), taking into account MODIS' lack of stratospheric channels and far higher horizontal resolution. The profile retrieval algorithm 
requires calibrated, navigated, and co-registered 1-km field of the view (FOV) radiances from MODIS channels 20, 22-25, 27-29, and 30-36. The atmospheric water vapor is most directly obtained by integrating the moisture profile through the atmospheric column. Data validation was conducted by comparing results from the Aqua platform with in situ data (Menzel et al., 2002). In the present study, air temperature and dew point temperature at $1000 \mathrm{hPa}$ level are used to calculate the vapor pressure deficit. Also the temperatures are assumed to be homogenous over the $5 \times 5 \mathrm{~km}$ grid.

\section{Results}

In this section, the results are divided in two parts. The results of variables and parameters needed to apply the CR models are presented in first place, followed by a comparison of results between equations (7) and (8).

\subsection{Variables calculation}

In order to apply Bouchet's and Granger's CR, Rn, G and F for each pixel of every image of the study area must be computed. The other parameters, $\Delta$ and $\gamma$, can be assumed constant for the entire region. Alternatively, they can be estimated with spatially distributed information of Ta over the region. The constants a and $\mathrm{k}$ are assumed equal to 1.26 and 2, respectively.

The Rn maps were estimated with the methodology published by Bisht et al. (2005), which provides a spatially consistent and distributed Rn map over a large domain for clear sky days. With this method, Rn can be evaluated in terms of its components of downward and upward short wave radiation fluxes, and downward and upward long wave radiation fluxes. Several MODIS data products are utilized to estimate every component. Details of these calculations for the study days presented in this work can be found in Bisht et al. (2005), from where we took the Rn maps.

Soil heat fluxes G were calculated according to Moran et al. (1989) with the daily Normalized Difference Vegetation Index (NDVI) maps (Kogan et al., 2003), calculated with MOD021KM products. The equations used are

$$
\begin{array}{cc}
G=0.583 R n \mathrm{e}^{\left(2.13^{*} N D V I\right)} & \text { for NDVI }>0 \\
G=0.583 \mathrm{Rn} & \text { for NDVI } \leq 0
\end{array}
$$

The slope of the SVP curve, $\Delta$, was calculated at Ta using Buck's equation (Buck, 1981) and the MODIS Ta product.

In order to determine $\mathrm{F}$, a methodology to estimate $\mathrm{Tu}$ is needed. By definition, different types of soils and water content would render different Tu values. Here, it is proposed to estimate the variable Tu from the SVP curve. It can be assumed that $e_{s}$ is larger or equal to $e_{a}$ and lower or equal to $\mathrm{e}_{\mathrm{s}}^{*}$, thus Tu must lie between $\mathrm{Ts}$ and $\mathrm{Td}$.

The first derivative of the SVP curve at Ts and at Td represents the slope of the curve between those points. It can also be computed from the linearized SVP curve between the intervals [Tu,Ts] and [Td,Tu], which are symbolized as $\Delta_{1}$ and $\Delta_{2}$, respectively. Thus, an expression for $\mathrm{Tu}$ is derived from a simple system of two equations with two unknowns, as follows,

$$
T_{u}=\frac{\left(e_{s}^{*}-e_{a}\right)-\Delta_{1} T s+\Delta_{2} T d}{\Delta_{2}-\Delta_{1}}
$$


There are many published SVP equations that can be used to obtain the derivative of e as function of the temperature. Here, Buck's formulation (Buck, 1981) was chosen for its simple form (equation 14),

$$
e=6.1121 \exp \left(\frac{17.502 \mathrm{~T}}{240.97+T}\right)
$$

where " $\mathrm{e}$ " is water vapor pressure $[\mathrm{hPa}]$ and $\mathrm{T}$ is temperature $\left[{ }^{\circ} \mathrm{C}\right]$. Thus, the first derivative of equation 14 is computed at $\mathrm{Td}$ and Ts to estimate $\Delta_{1}$ and $\Delta_{2}$ in equation (13).

$$
\frac{d e}{d T}=\left[\frac{4217.45694}{(240.97+\mathrm{T})^{2}}\right] * 6.1121 \exp \left(\frac{17.502 \mathrm{~T}}{240.97+T}\right)
$$

The estimation of Tu could be improved by introducing another surface variable, such as soil moisture or any other surface variable that accounts for the surface wetness. However, in order to demonstrate the strength of the CR models, the Tu calculation is kept simple, with minimum data requirements. It is recognized, however, that this calculation simplifies the physical process and may introduce errors and uncertainties to the F ratio.

Figure 5 shows Rn maps obtained for April 1st, 2003 as an example of what can be expected in terms of spatial resolution with Bisht et al. methodology. Figure 6 displays Tu map for the same date obtained with the MOD07 spatial resolution $(5 \times 5 \mathrm{~km})$.

\subsection{Comparison of the CR models}

The results obtained from equations (7) and (8) are compared to demonstrate the strength of the complementary relationship. The contrasted results were computed assuming $\mathrm{k}=2$, $\mathrm{a}=1.26, \gamma=0.67 \mathrm{hPa} / \mathrm{C}, \Delta$ was obtained with Ta maps, estimating $\mathrm{F}$ as proposed in Venturini et al. (2008). The resulting ET estimates are shown in Table 4, where average root mean square errors (RMSEs) and biases are about $25 \mathrm{Wm}^{-2}$, indicating that equation (7), obtained with Bouchet's complementary model, would lead to larger ET estimates. However, only the "ground truth" would tell which equation is more precise. In this case, the ground truth is considered to be the ground measurements of ET described in section 4.2. Then, observed ET values were compared with the results obtained using equations (7) and (8), (see Figure 7). The overall RMSE is about 52.29 and the bias (Observed-Bouchet) is $-37.90 \mathrm{Wm}^{-2}$. For Granger`s CR, the overall RMSE and bias (Observed-Granger) are 33.89 and $-10.96 \mathrm{Wm}^{-2}$ respectively, with an $R^{2}$ of about 0.79 .

\begin{tabular}{lccc}
\hline & RMSE & BIAS (Bouchet-Granger) & $\mathbf{R}^{2}$ \\
\hline DOY82 & 5.42 & 0.91 & 0.990 \\
DOY90 & 7.38 & 0.86 & 0.993 \\
DOY91 & 13.70 & 13.01 & 0.983 \\
DOY 249 & 31.74 & 31.56 & 0.995 \\
DOY 262 & 25.51 & 25.33 & 0.991 \\
DOY 285 & 26.79 & 26.40 & 0.990 \\
DOY 292 & 28.24 & 28.11 & 0.999 \\
\hline
\end{tabular}

Table 4. ET $\left(\mathrm{Wm}^{-2}\right)$ comparison between Bouchet's and Granger's CR. 
From Table 4 it can be concluded that Bouchet's simplification results in larger ET estimates, with biases up to approximately $32 \mathrm{Wm}^{-2}$, than those obtained with Granger`s CR. From Figure 7 it can be seen that Bouchet`s CR overestimates ground observations as well.

Ramírez et al. (2005) derived the value of Bouchet's k parameter from ground data. The authors presented evidences of the complementary relationship from independent measurements of ET and Epot. Then, $\mathrm{k}$ values were calculated for different hypothesis. These authors reported a mean $\mathrm{k}$ of about 2.21 and a $\mathrm{k}$ variance equal to 0.07 using uncorrected pan evaporation data as a surrogate of Epot.

In this chapter, equations (7) and (8) are equated and k calculated for instantaneous ET values. Thus,

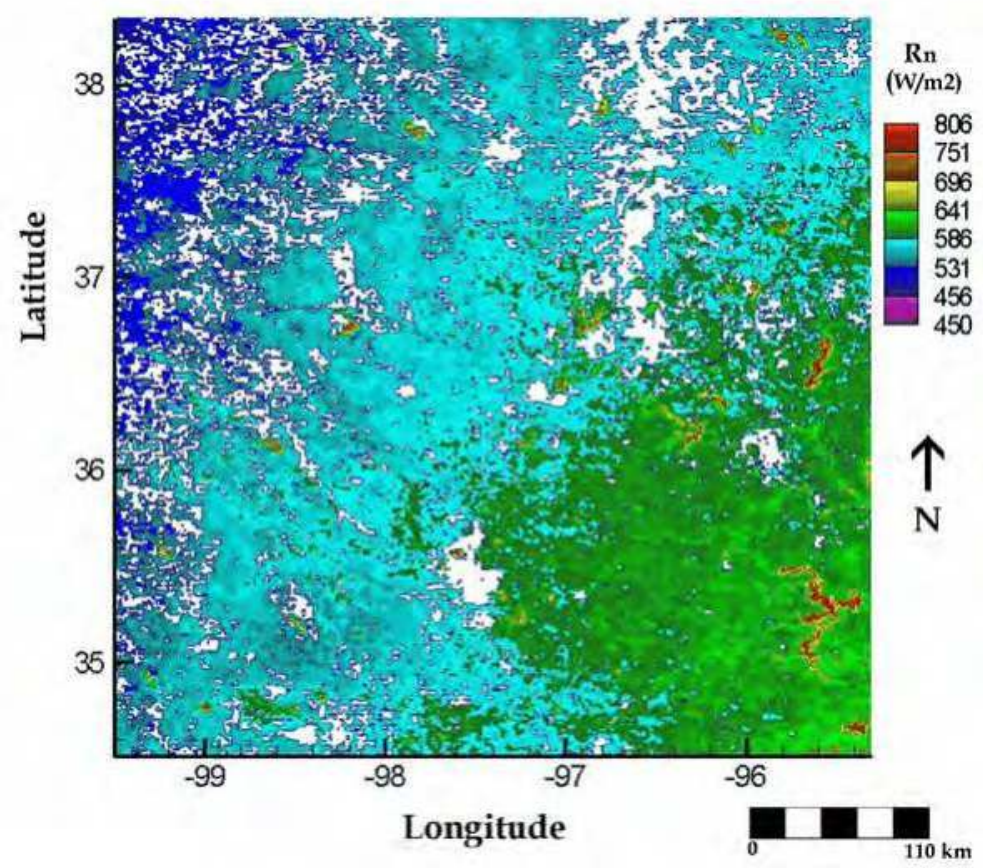

Fig. 5. Net radiation map of the SGP for April 1st, 2003

$$
\begin{gathered}
\frac{F \Delta}{F \Delta+\gamma}=\frac{k F \Delta}{(F+1)(\Delta+\gamma)} \\
k=\frac{(F+1)(\Delta+\gamma)}{F \Delta+\gamma}
\end{gathered}
$$

Bouchet's coefficient $\mathrm{k}$ was calculated for each pixel in every day. The overall mean $\mathrm{k}$ value is 2.341 , with an overall minimum of 1.784 and a maximum of 2.710 , standard deviations varying from 0.025 to 0.078 . These results are close to those reported by Ramírez et al. (2005). 


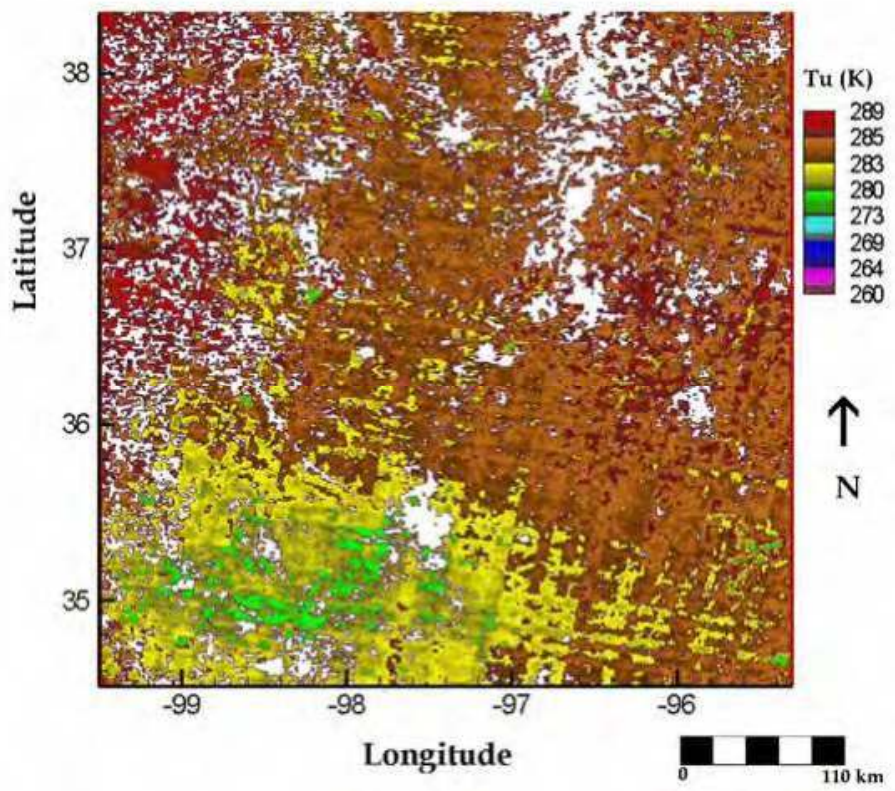

Fig. 6. Tu map of the SGP for April 1st, 2003

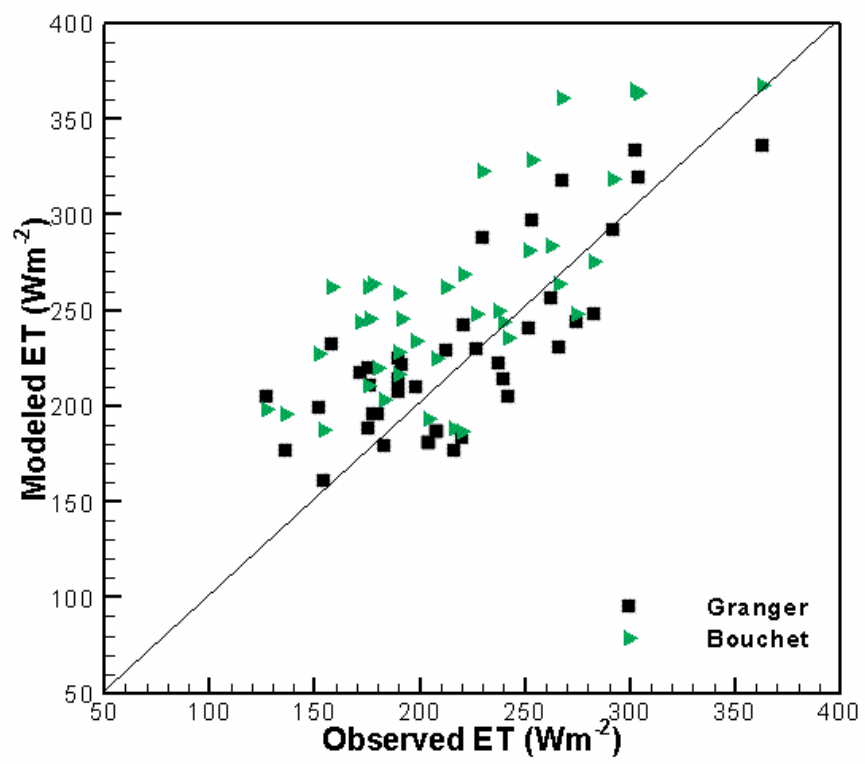

Fig. 7. Comparison between Bouchet's and Granger`s complementary models against ground measurements 
Both complementary models yield similar ET estimates, however Granger's model lead to more accurate results than Bouchet's method. The slope of the SVP curve at the air temperature sets a k value slightly different from 2 .

\section{Spatial and temporal scales considerations}

The complementary theory assumes a surface without advection influences and so does the regional evapotranspiration concept (Penman, 1948; Priestly \& Taylor, 1972; Brutsaert \& Stricker 1979). In fact, in his original work, Bouchet (1963) described five scales implicated in the oasis effect (see Table 5). Therefore for each scale of heterogeneity (s), we can define the oasis effects that give the lateral energy exchange of $Q_{1}, Q_{2}, Q_{3}, Q_{4}, Q_{5}$. In the development of his theory he assumed that only $\mathrm{Q}_{3}$ is variable with ET while $\mathrm{Q}_{4}$ and $\mathrm{Q}_{5}$ are not affected by changes of ET and Epot associated with water availability. For the other two scales, $s_{1}$ and $s_{2}$, $Q_{1}$ and $Q_{2}$ are not involved in the complementary relationship. Bouchet's experiment established an energy balance over 24 hours, avoiding taking into account the phenomena of accumulation and restoration of heat during the day and night phases. These particular assumptions left smaller time and space scales out of the $C R$, therefore a review of the scales of applicability of the CR might be interesting.

The "evaporation paradox" mentioned by Brutsaert \& Parlange (1998) refers to the seemingly opposing trends observed between pan evaporation and actual evaporation. The authors suggested that the paradox is solved in the CR framework.

The usefulness of the CR for understanding global scale in climate studies have been analized by Brutsaert \& Parlange (1998), Szilagyi (2001) and Hobbins et al. (2001), among others. Szilagy \& Josza, (2009), coupled Bouchet's CR with a long-term water-energy balance based on considerations of the precipitation time series and the soil water balance. The authors show that important ecosystem characteristics, such as the maximum soil water storage, can be derived from this "long-term" application of the CR. The scales shown in Table 5 seem to be compatible with those used in the aforementioned works. Nonetheless, the applicability of the CR at small scales is not evident from Bouchet's publication.

Crago \& Crowley (2005) evaluated the complementary relationship at relatively small temporal scales (10 to $30 \mathrm{~min}$ ) using data from meteorological stations in different grassland sites. The authors demonstrated that the CR holds true also at small scales. Kahler and Brutsaert (2006) used properly scaled data of daily ET and daily pan evaporation observed at two experimental sites to demonstrate the validity of the CR. The CR at daily scales was confirmed by this research. The authors argue that for unscaled daily data of pan evaporation the CR may not be noticeable.

\begin{tabular}{|c|c|c|c|}
\hline $\begin{array}{c}\text { Scale } \\
\text { (symbol in the text) }\end{array}$ & Timescales & Spatial Scales & $\begin{array}{c}\text { Effects of oasis } \\
\text { corresponding }\end{array}$ \\
\hline Molecular $-\mathrm{s}_{1}$ & $10^{\prime 9}$ second & few hundred meters & $Q_{1}$ \\
\hline Turbulent $-s_{2}$ & $\begin{array}{c}1 \text { second to some } \\
\text { minutes }\end{array}$ & few hundred meters & $Q_{2}$ \\
\hline $\begin{array}{c}\text { Convection and related } \\
\text { movements }-s_{3}\end{array}$ & $\begin{array}{c}10 \text { minutes to a few } \\
\text { hours }\end{array}$ & few kilometers & $Q_{3}$ \\
\hline Cyclonic $-s_{4}$ & 3 to 4 hours & 1000 a 2000 kilometers & $Q_{4}$ \\
\hline Global $-s_{5}$ & 10 to 30 hours & 5000 to 10000 km & $Q_{5}$ \\
\hline
\end{tabular}

Table 5. Translation of Table 1 published by Bouchet in 1963 
In a more practical way, the method proposed by Venturini et al. (2008) corrects the ET from a saturated surface with the local surface-atmosphere conditions at the pixel scale. The absence of regional assumptions makes the method applicable to a wide range of spatial scales even though the background of their method is Granger's CR. Venturini's method has been applied with instantaneous data, i.e. remotely sensed data with MODIS. The comparison between observed and estimated ET values yields errors of about $15 \%$ of observed instantaneous ET( Venturini et al., 2011).

\section{References}

Bastiaanssen, W.G.M., Menenti, M.A, Feddes, R.A. \& Hollslag, A.A.M. (1998). A remote sensing surface energy balance algorithm for land (SEBAL) 1. Formulation. Journal of Hydrology, 212, 13, pp. 198-212, ISSN 0022-1694.

Bastiaanssen, W.G.M. (2000). SEBAL-based sensible and latent heat fluxes in the irrigated Gediz Basin, Turkey. Journal of Hydrology, 229, pp. 87-100, ISSN 0022-1694.

Bisht, G., Venturini, V., Jiang, L. \& Islam, S. (2005). Estimation of Net Radiation using MODIS (Moderate Resolution Imaging Spectroradiometer) Terra Data for clear sky days. Remote Sensing of Environment, 97, pp. 52-67, ISSN 0034-4257.

Bouchet, R.J. (1963). Evapotranspiration rèelle et potentielle, signification climatique. International Association of Scientific Hydrology, 62, pp. 134-142, ISSN 0262-6667.

Brutsaert, W., \& Stricker, H. (1979). An advection-aridity approach to estimate actual regional evapotranspiration. Water Resources Research, 15,2, pp. 443-450, ISSN 00431397.

Brutsaert W., \& Parlange M.B. (1998) Hydrologic cycle explains the evaporation paradox. Nature, 396, pp. 30, ISSN 0028-0836.

Buck, A.L. (1981). New equations for computing vapor pressure and enhancement factor. Journal of Applied Meteorology, 20, pp. 1527-1532, ISSN 0894-8763.

Calvet, J.C., Noilhan , J. \& Besseoulin, P. (1998). Retrieving the root zone soil moisture from surface soil moisture or temperature estimates: A feasibility study on field measurements. Journal of Applied Meteorology, 37, pp. 371-386, ISSN 0894-8763.

Carlson, T.N., Gillies, R.R., \& Schmugge, T. J. (1995). An interpretation of methodologies for indirect measurement of soil water content. Agricultural and Forest Meteorology, 77, pp. 191-205, ISSN 0168-1923.

Courault, D., Seguin, B. \& Olioso, A. (2005). Review to estimate Evapotranspiration from remote sensing data: Some examples from the simplified relationship to the use of mesoscale atmospheric models. Irrigation and Drainage Systems, 19, pp. 223-249, ISSN 0168-6291.

Crago, R., \& Crowley, R. (2005). Complementary relationship for near-instantaneous evaporation. Journal of Hydrology, 300, pp. 199-211, ISSN 0022-1694.

Crago, R., Hervol, N., \& Crowley, R. (2005). A complementary evaporation approach to the scalar roughness length. Water Resources Research, 41, W06017, ISSN 0043-1397.

Crago, R.D., Qualls R.J., \& Feller M. (2010) A calibrated advection-aridity evaporation model requiring no humidity data. Water Resources Research, 46, W09519, doi:10.1029/2009WR008497, (September, 2010), ISSN. 0043-1397.

Fritschen, L., \& Simpson, J. R. (1989). Surface energy and radiation balance systems: General description and improvements. Journal of Applied Meteorology 28, 680-689. ISSN 0894-8763. 
Granger, R.J. (1989a). An examination of the concept of potential evaporation. Journal of Hydrology, 111, pp. 9-19, ISSN 0022-1694.

Granger, R.J., \& Gray, D.M. (1989). Evaporation from natural nonsaturated surfaces. Journal of Hydrology, 111, pp. 21-29, ISSN 0022-1694.

Granger, R.J. (1989b). A complementary relationship approach for evaporation from nonsaturated surfaces. Journal of Hydrology, 111, pp. 31-38, ISSN 0022-1694

Granger, R.J., \& Gray, D.M. (1990). Examination of Morton's CRAE model for estimating daily evaporation from field-sized areas. Journal of Hydrology, 120, pp. 309-325, ISSN 0022-1694.

Halldin, S \& Lindroth, A. (1992). Errors in net radiometry: Comparison and evaluation of six radiometer designs. Journal of Atmospheric Oceanic Technology, 9, 762-783, ISSN 0739-0572.

Han, S., Hu, H., Yang, D., \& Tian, F. (2011). A complementary relationship evaporation model referring to the Granger model and the advection-aridity model. Hydrological Processes, 25, 8, doi:10.1002/hyp.7960, ISSN 0885-6087.

Heilman, J.L. \& Brittin, C. L. (1989). Fetch requirements for Bowen ratio measurements of latent and sensible heat fluxes. Agricultural and Forest Meteorology, 44, 261-273, ISSN 0168-1923.

Hobbins, M.T., \& Ramírez, J.A. (2001). The complementary relationship in estimation of regional evapotranspiration: An enhanced advection-aridity model, Water Resources Research, 37,5, pp. 1389-1403, ISSN 0043-1397.

Hobbins, M.T., Ramírez, J.A., Brown T.C. \& Classens L.H.J.M. (2001). The complementary relationship in estimation of regional evapotranspiration: The complementary relationship areal evapotranspiration and advection-aridity models, Water Resources Research, 37,5, pp. 1367-1487, ISSN 0043-1397.

Holwill, C.J., \& Stewart, J.B. (1992). Spatial variability of evaporation derived from Aircraft and ground-based data. Journal of Geophysical Research, 97, D17, pp. 19061-19089, ISSN 0148-0227

Jackson, R.D., Reginato, R.J., \& Idso, S.B. (1977). Wheat canopy temperature: A practical tool for evaluating water requirements. Water Resources Research, 13, pp. 651-656, ISSN 0043-1397

Jiang, L. \& Islam, S. (2001). Estimation of surface evaporation map over southern Great Plains using remote sensing data. Water Resources Research, 37(2), 329-340. ISSN 0043-1397.

Kahler, D. M. \& Brutsaert, W. (2006). Complementary relatinship between daily evaporation in the environment and pan evaporation. Water Resources Research, 42, W05413, doi:10.1029/2005WR004541, ISSN 0043-1397.

Kogan, F., Gitelson, A., Zakarin, E., Spivak, L. \& Lebed, L., (2003). AVHRR-Based Spectral Vegetation Index for Quantitative Assessment of Vegetation State and Productivity: Calibration and Validation. Photogrammetric Engineering \& Remote Sensing, 69, 8, (August 2003) pp. 899-906, ISSN 0099-1112.

Lhomme J.P., \& Guilione L. (2006). Comments on some articles about the complementary relationship, Discussion. Journal of Hydrology, 323, pp. 1-3, ISSN 0022-1694.

Menzel, W.P., Seemann, S.W., Li, J., \& Gumley, L.E. (2002). MODIS Atmospheric Profile Retrieval Algorithm Theoretical Basis Document, Version 6. Reference Number: ATBDMOD-07. NASA. http://modis.gsfc.nasa.gov/data/atbd/atbd_mod07.pdf. 
Monin, A.S. \& Obukhov, A.M., (1954). Osnovnye zakonomernosti turbulentnogo peremesivanija $\mathrm{v}$ prizemnom sloe atmosfery. Trudy Geofizicheskogo Instituta Akademiya Nauk SSSR, 24, 151, pp. 163-187.

Monteith, J.L. \& Unsworth, M. (1990). Principles of Environmental Physics (2nd edition), Butterworth-Heinemann, ISBN: 071312931X, Burlington-MA- USA.

Moran, M.S., Jackson, R.D., Raymond, L.H, Gay, L.W. \& Slater, P.N. (1989). Mapping surface energy balance components by combining LandSat thematic mapper and groundbased meteorological data, Remote Sensing of Environment, 30, pp.77-87, ISSN 00344257.

Morton, F. I. (1969). Potential evaporation as manifestation of regional evaporation. Water Resources Research, 5, pp. 1244-1255, ISSN 0043-1397.

Morton, F.I. (1983). Operational estimates of areal evapotranspiration and their significance to the science and practice of hydrology. Journal of Hydrology, 66, 1-76, ISSN $0022-$ 1694.

Nishida, K., Nemani, R.R., Running, S.W. \& Glassy, J.M. (2003). An operational remote sensing algorithm of land evaporation. Journal of Geophysical Research, 108, D9, 4270, doi:10.1029/2002JD002062, ISSN 0148-0227.

Noilhan, J. \& Planton, S. (1989). GCM gridscale evaporation from mesoscale modelling. Journal of Climate, 8, pp. 206-223, ISSN 0894-8755

Norman, J.M., Kustas, W.P. \& Humes, K.S. (1995). Sources approach for Estimating soil and vegetation energy fluxes in observations of directional radiometric surface temperature. Agricultural Forest and Meteorology, 77, pp. 263-293, ISSN 0168-1923.

Ozdogan M., Salvucci G.D., \& Anderson B.T. (2006). Examination of the Bouchet-Morton complementary relationship using a mesoscale climate model and observations under a progressive irrigation scenario, Journal of Hydrometeorology, 7, pp. 235-251, ISSN 1525-755X

Penman, H.L. (1948). Natural evaporation from open water, bare soil and grass. Proceedings of the Royal Society of London, Series A, 193,1032,(April, 1948), pp. 120-145, ISSN 14712946.

Price, J.C. (1990). Using spatial context in satellite data to infer regional scale evapotranspiration. IEEE Transactions on Geoscience and Remote Sensing, 28, 5, pp. 940-948, ISSN 0196-2892

Priestley, C.H.B. \& Taylor, R.J. (1972). On the Assessment of Surface Heat Flux and Evaporation Using Large-Scale Parameters. Monthly Weather Review, 100, pp. 81-92, ISSN 0027-0644.

Ramírez, J.A., Hobbins, M.T. \& Brown T. (2005). Observational evidence of the complementary relationship in regional evaporation lends strong support for Bouchet's hypothesis. Geophysical Research Letters, 32, L15401, doi:10.1029/2005GL023549, ISSN 0094-8276.

Rivas, R. \& Caselles, V. (2004). A simplified equation to estimate spatial reference evaporation from remote sensing-based surface temperature and local meteorological data. Remote Sensing of Environment, 83, pp. 68-76, ISSN 0034-4257.

Seguin, B., Assad, E., Fretaud, J.P., Imbernom, J.P., Kerr, Y., \& Lagouarde, J.P. (1989). Use of meteorological satellite for rainfall and evaporation monitoring. International Journal of Remote Sensing, 10, pp. 1001-1017, ISSN 0143-1161. 
$\mathrm{Su}$, B. (2002). The surface energy balance system (SEBS) for estimation of turbulent heat fluxes. Hydrology and Earth System Sciences, 6, pp. 85-99, ISSN 1027-5606.

Sugita, M., Usui, J., Tamagawa, I. \& Kaihotsu, I. (2001).Complementary relationship with a convective boundary layer to estimate regional evaporation. Water Resources Research, 37,2, pp. 353-365, ISSN 0043-1397.

Szilagyi J., (2001). On Bouchet's complementary hypothesis. Journal of Hydrology, 246, pp. 155-158, ISSN 0022-1694.

Szilagyi J. (2007). On the inherent asymmetric nature of the complementary relationship of evaporation, Geophysical Research Letters, 34, L02405, ISSN 0094-8276.

Szilagyi J., \& Jozsa J. (2008). New findings about the complementary relationship based evaporation estimation methods. Journal of Hydrology, 354, pp. 171- 186, ISSN 00221694.

Szilagyi J., \& Jozsa J. (2009). Analytical solution of the coupled 2-D turbulent heat and vapor transport equations and the complementary relationship of evaporation . Journal of Hydrology, 372, pp. 61-67, ISSN 0022-1694.

van Bavel, C.H.M. (1966). Potential evaporation: The combination concept and its experimental verification. Water Resources Research , 2, pp. 455-467, ISSN 0043-1397.

Venturini, V., Islam, S., \& Rodríguez, L., (2008). Estimation of evaporative fraction and evapotranspiration from MODIS products using a complementary based model. Remote Sensing of Environment. 112, pp. 132-141, ISSN 0034-4257.

Venturini, V., Rodriguez L., \& Bisht G. (2011). A comparison among different modified Priestley and Taylor's equation to calculate actual evapotranspiration". International Journal of Remote Sensing, In Press, ISSN 0143-1161

$\mathrm{Xu}$, C.Y., \& Singh, V.P. (2005). Evaluation of three complementary relationship evapotranspiration models by water balance approach to estimate actual regional evapotranspiration in different climatic regions. Journal of Hydrology, 308, pp. 105121, ISSN 0022-1694.

Wan, Z. (1999). MODIS Land-Surface Temperature Algorithm Basis Document (LST ATBD), version 3.3, NASA, www.icess.ucsb.edu/modis/atbd-mod-11.pdf. 


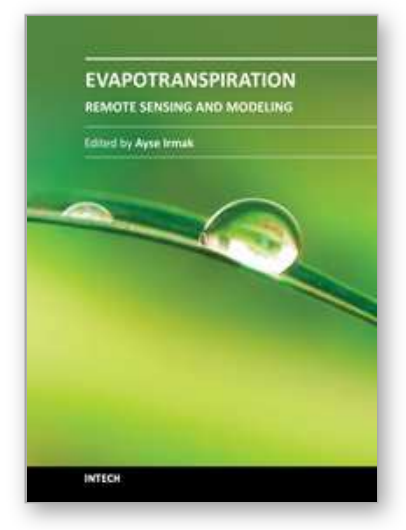

\author{
Evapotranspiration - Remote Sensing and Modeling \\ Edited by Dr. Ayse Irmak
}

ISBN 978-953-307-808-3

Hard cover, 514 pages

Publisher InTech

Published online 18, January, 2012

Published in print edition January, 2012

This edition of Evapotranspiration - Remote Sensing and Modeling contains 23 chapters related to the modeling and simulation of evapotranspiration (ET) and remote sensing-based energy balance determination of ET. These areas are at the forefront of technologies that quantify the highly spatial ET from the Earth's surface. The topics describe mechanics of ET simulation from partially vegetated surfaces and stomatal conductance behavior of natural and agricultural ecosystems. Estimation methods that use weather based methods, soil water balance, the Complementary Relationship, the Hargreaves and other temperatureradiation based methods, and Fuzzy-Probabilistic calculations are described. A critical review describes methods used in hydrological models. Applications describe ET patterns in alpine catchments, under water shortage, for irrigated systems, under climate change, and for grasslands and pastures. Remote sensing based approaches include Landsat and MODIS satellite-based energy balance, and the common process models SEBAL, METRIC and S-SEBS. Recommended guidelines for applying operational satellite-based energy balance models and for overcoming common challenges are made.

\title{
How to reference
}

In order to correctly reference this scholarly work, feel free to copy and paste the following:

Virginia Venturini, Carlos Krepper and Leticia Rodriguez (2012). Evapotranspiration Estimation Based on the Complementary Relationships, Evapotranspiration - Remote Sensing and Modeling, Dr. Ayse Irmak (Ed.), ISBN: 978-953-307-808-3, InTech, Available from: http://www.intechopen.com/books/evapotranspirationremote-sensing-and-modeling/evapotranspiration-estimation-based-on-the-complementary-relationships

\section{INTECH}

open science | open minds

\section{InTech Europe}

University Campus STeP Ri

Slavka Krautzeka 83/A

51000 Rijeka, Croatia

Phone: +385 (51) 770447

Fax: +385 (51) 686166

www.intechopen.com

\section{InTech China}

Unit 405, Office Block, Hotel Equatorial Shanghai

No.65, Yan An Road (West), Shanghai, 200040, China 中国上海市延安西路65号上海国际贵都大饭店办公楼 405 单元

Phone: +86-21-62489820

Fax: +86-21-62489821 
(C) 2012 The Author(s). Licensee IntechOpen. This is an open access article distributed under the terms of the Creative Commons Attribution 3.0 License, which permits unrestricted use, distribution, and reproduction in any medium, provided the original work is properly cited. 